Christian, J. H. B. \& Ingram, M. (1959). J. gen. Microbiol. 20, 32-42

\title{
Lysis of Vibrio costicolus by Osmotic Shock
}

\author{
By J. H. B. CHRISTIAN* AND M. INGRAM \\ Low Temperature Station for Research in Biochemistry and Biophysics, \\ University of Cambridge and Department of Scientific and Industrial Research
}

SUMMARY: Suspensions of the halophilic organism Vibrio costicolus lysed when subjected to sufficient osmotic shock; this was revealed as a marked fall in optical density. Organisms in the logarithmic phase of growth, grown in media containing $\mathrm{M}-\mathrm{NaCl}$, when suspended in $\mathrm{NaCl}$ or $\mathrm{LiCl}$ solutions with concentrations $\mathrm{M}$ or lower lysed when the concentration was below $0.33 \mathrm{~m}$ : when the organisms were suspended similarly in $\mathrm{KCl}$ or $\mathrm{NH}_{4} \mathrm{Cl}$ solutions, lysis began at a concentration above $0.8 \mathrm{M}$. Older organisms were more resistant to lysis. Lysis was little affected by replacement of chloride by other univalent anions, by $\mathrm{pH}$ values from 4 to 10 or by previous incubation with $10^{-5} \mathrm{M}$-mercuric chloride. Addition of cetyltrimethylammonium bromide $(200 \mu \mathrm{g} . / \mathrm{ml}$.) increased resistance to lysis in both $\mathrm{NaCl}$ and $\mathrm{KCl}$ solutions.

Organisms grown in media of $\mathrm{NaCl}$ concentrations ranging from 0.5 to $3.0 \mathrm{M}$ began to lyse at a NaCl concentration one-third of that present during growth. Organisms suspended in $\mathrm{NaCl}$ solutions of one-half the concentration in which they had been grown equilibrated promptly to the new environment; this was shown by a decrease of $50 \%$ in the salt concentration at which lysis then began. When organisms were transferred to salt concentrations higher than that of the growth medium, the osmotic sensitivity was not affected. It is concluded that the osmotic status of these organisms is controlled chiefly by small ions or molecules which leak rapidly from the cells on transfer to dilute environments.

Many types of bacteria lyse when transferred from concentrated growth media to more dilute solutions or to water, and this behaviour is particularly common among halophilic strains. Robinson \& Katznelson (1953) noted that the extremely halophilic Pseudomonas salinaria, grown in a medium containing $16 \%(\mathrm{w} / \mathrm{v}) \mathrm{NaCl}$, underwent rapid plasmoptysis on transfer to 1,2 or $4 \% \mathrm{NaCl}$ and showed some deterioration of structure in $8 \% \mathrm{NaCl}$. However, no attempts appear to have been made to study quantitatively the degree of lysis resulting from osmotic shock. Christian \& Ingram (1959) found that the freezing-point depression of heated bacteria was similar to that of their growth medium over a wide range of salt concentrations. It was of interest, therefore, to investigate the relationship between the osmotic sensitivity of such organisms and the salt concentration of the environment. This paper describes a technique for measurement of osmotic lysis, and reports the effects of a number of factors on the osmotic sensitivity of a moderate halophile, Vibrio costicolus.

\section{METHODS}

Organism. The test organism was a strain of Vibrio costicolus kindly supplied by Dr J. M. Shewan.

Media. The organism was grown in liquid media containing $0.5 \%(\mathrm{w} / \mathrm{v})$

* Present address : Division of Food Preservation and Transport, Commonwealth Scien. tific and Industrial Research Organization, Homebush, N.S.W., Australia. 
each of proteose peptone (Difco) and tryptone (Difco) with additions of $\mathrm{NaCl}$. The initial $\mathrm{pH}$ value was $\mathbf{7 \cdot 0}$. Media for maintaining stock cultures and for growing inocula contained $4 \%(\mathrm{w} / \mathrm{v}) \mathrm{NaCl}$. All cultures were incubated at $25^{\circ}$.

Lysis technique. Cultures were grown in $200 \mathrm{ml}$. volumes of medium of appropriate $\mathrm{NaCl}$ content, aerated by shaking, in Fernbach flasks. Organisms were harvested in the logarithmic phase of growth and a thick suspension prepared in a solution of the appropriate salt. Except where otherwise stated, this solution was equimolar with the salt concentration used in the growth medium; and the concentration of organisms was chosen to give a reading about 30 on an E.E.L. colorimeter after tenfold dilution with the same salt solution. To produce osmotic shock, $1 \mathrm{ml}$. portions of the stock suspension were pipetted into ten $9 \mathrm{ml}$. volumes of graded concentrations of the same salt solution, and the mixtures stirred thoroughly. At least 2 min. were next allowed for equilibration and clearance of bubbles; beyond this, the time was not critical. The optical densities of the mixtures were measured in the E.E.L. colorimeter at a wavelength of about $450 \mathrm{~m} \mu$. These values are recorded graphically as percentage of the optical density of the suspension in the highest salt concentration tested. Variations in the $\mathrm{NaCl}$ content of the growth medium and in the nature and concentration of the salts used in the lysis experiments are described later.

\section{RESULTS}

For the sake of clarity, the main results are first presented in section $\mathbf{A}$, assuming that changes in optical density correctly indicated the lysis of the cells, this assumption being justified later in section $\mathrm{B}$.

\section{A. The influence of conditions on lysis}

The factors $\mathrm{pH}$ value and temperature proving relatively unimportant (see later), interest centred on the salt relations of the organisms.

Lysis in sodium chloride solutions. The relationship between $\mathrm{NaCl}$ concentration and optical density after osmotic shock for organisms grown in $\mathbf{M}-\mathrm{NaCl}$ medium is shown in Fig. 1. The decrease in optical density, as the salt concentration was decreased from 1.0 to $0.7 \mathrm{M}$, was presumably due to osmotic swelling (cf. Mitchell \& Moyle, 1956). The more rapid decrease at salt concentrations below $0.4 \mathrm{M}$ was due to the lysis of an increasing proportion of the organisms, as will be shown later. At these low concentrations, the turbidity decreased rapidly as soon as the organisms were mixed with the diluting solutions and most of the time lag ( $<2 \mathrm{~min}$.) was due to slow clearing of air bubbles in the viscous lysate.

The shape of the curve in Fig. 1 is probably sigmoid, but the inflexion between the values $0 \cdot 3$ and $0 \cdot 4 \mathrm{M}$ is nevertheless well defined. To determine the salt concentration at which lysis might be said to begin, the two linear portions of the curve were extrapolated to intersect as shown in Fig. 1. By rough analogy with the terminology of plasmolysis, the salt concentration corresponding with this intersection has been termed the "point of incipient 
lysis', or, simply, the 'lysis point'. Thus for logarithmic phase organisms, grown and suspended initially in $\mathrm{M}-\mathrm{NaCl}$, the lysis point was near $0.33 \mathrm{M}$. This value was obtained in most experiments, with occasional variations of $0.01 \mathrm{M}$. For organisms harvested in the stationary phase of growth, the lysis point was $0 \cdot 2 \mathrm{M}$.

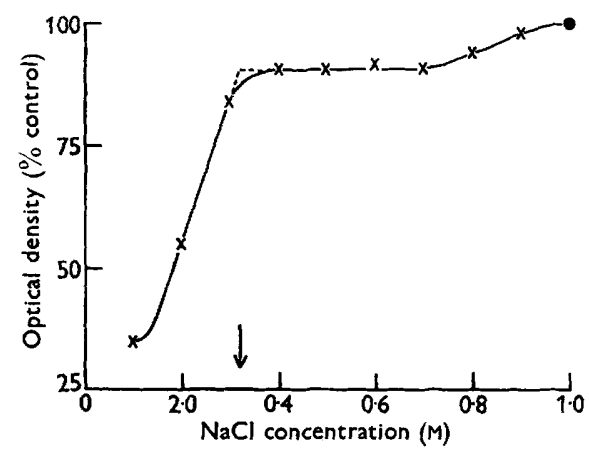

Fig. 1

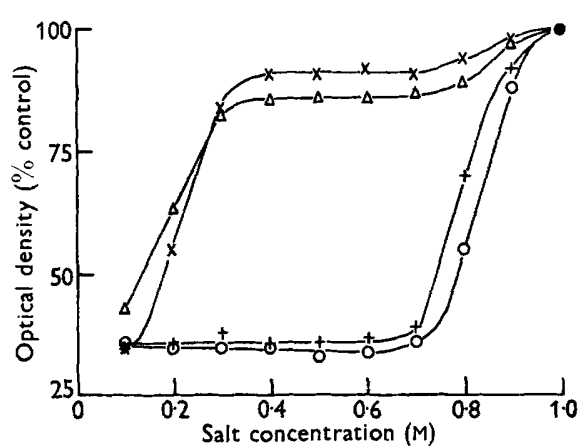

Fig. 2

Fig. 1. Effect of osmotic shock on the optical density of suspensions of Vibrio costicolus. Organisms were harvested in the logarithmic phase of growth from media containing $\mathrm{M}-\mathrm{NaCl}$. The arrow indicates the concentration at which lysis commences.

Fig. 2. Effect of osmotic shock in salt solutions on the optical density of suspensions of $V$ ibrio costicolus $\times, \mathrm{NaCl} ; \triangle, \mathrm{LiCl} ; \mathrm{O}, \mathrm{KCl} ;+, \mathrm{NH}_{4} \mathrm{Cl}$. Organisms were grown in media containing $\mathrm{M}-\mathrm{NaCl}$.

Lysis in solutions of other salts. Figure 2 shows the optical density curves obtained when organisms grown in medium containing $\mathrm{M}-\mathrm{NaCl}$ were suspended in $\mathrm{M}$ solutions of $\mathrm{LiCl}, \mathrm{NaCl}, \mathrm{KCl}$ or $\mathrm{NH}_{4} \mathrm{Cl}$ and subsequently diluted in the corresponding salt. In $\mathrm{LiCl}$ (and in $\mathrm{MgCl}_{2}$ ) the results were very similar to those in $\mathrm{NaCl}$. On the other hand, $\mathrm{KCl}$ and $\mathrm{NH}_{4} \mathrm{Cl}$ afforded very little osmotic protection, and organisms began to lyse at concentrations near $0.9 \mathrm{M}$.

Other univalent anions (bromide, nitrate, thiocyanate, acetate) behaved similarly to chloride, with either sodium or potassium as cation. Sulphate was tested as a representative bivalent anion, giving twice the concentration of cations found in the corresponding uni-univalent salt solutions. In $\mathrm{Na}_{2} \mathrm{SO}_{4}$, typical lysis occurred at concentrations just below $0 \cdot 2 \mathrm{M}$; i.e. the lysis point was at a $\mathrm{Na}^{+}$concentration between 0.3 and $0.4 \mathrm{M}$ as in $\mathrm{NaCl}$ solutions. In $\mathrm{K}_{2} \mathrm{SO}_{4}$ the optical density began to fall at $0 \cdot 8 \mathrm{M}$, but the subsequent decrease was less sharp than in $\mathrm{KCl}$, so that the lysis point was ill-defined; it was, however, at a $\mathrm{K}^{+}$concentration near $\mathrm{M}$, thus corresponding roughly with the situation in $\mathrm{KCl}$ represented in Fig. 2 (and Fig. 5). Because the lysis points are much the same in sulphate as in chloride solutions, when reckoned on cation concentration, while the great difference between sodium and potassium salts remains, the effects observed must be chiefly dependent on the nature of the cation.

Smithies, Gibbons \& Bayley (1955) found that the addition of $0 \cdot 15 \%$ (w/v) $\mathrm{CaCl}_{2}$ to the growth medium gave halophilic organisms from which improved 
preparations of cell envelope material could be obtained. Cell walls of such preparations were much more electron dense than those from organisms grown in normal medium. If these data indicate a strengthening of the cell wall by growth in $\mathrm{CaCl}_{2}$, an enhanced resistance to lysis might be expected. However, Vibrio costicolus grown under these conditions behaved in the same way as organisms grown normally, when subjected to osmotic shock in either sodium or potassium chlorides.

Lysis of washed organisms. When Vibrio costicolus organisms were washed once in the solution in which they were finally to be suspended, they acquired a slightly increased resistance to osmotic shock in $\mathrm{NaCl}$ and in $\mathrm{KCl}$. Since this change was variable and was probably due, at least in part, to ageing of the organisms, unwashed organisms were preferred for subsequent experiments.

Effect of temperature. The effect of temperature on lysis in sodium and potassium chloride solutions was examined by equilibrating duplicate batches of suspensions and salt solutions at $10^{\circ}$ and $37^{\circ}$. Subsequent dilutions and optical density readings were carried out at these same temperatures. Lysis in $\mathrm{KCl}$ solution was not affected by temperature. In $\mathrm{NaCl}$ solutions, however, the osmotic sensitivity increased with increase in temperature. Lysis began at $0.28 \mathrm{M}$ at $10^{\circ}$ and at $0.36 \mathrm{M}$ at $37^{\circ}$, compared with $0.33 \mathrm{M}$ at room temperature. Suspensions which had been heated for $10 \mathrm{~min}$. at $80^{\circ}$ had low optical densities and did not give typical lysis curves when diluted.

Effect of $p H$ value. All the lysis data given above refer to experiments in salt solutions without adjustment of $\mathrm{pH}$ value. To examine the effect of $\mathrm{pH}$ value on the reaction, organisms were diluted in : (i) unbuffered $\mathrm{NaCl}$ or $\mathrm{KCl}$ solutions adjusted to $\mathrm{pH}$ values over the range 4.0-10.0, with $\mathrm{HCl}$ and $\mathrm{NaOH}$ or $\mathrm{KOH}$, respectively; (ii) in solutions adjusted to $\mathrm{pH} 5.5$ and 8 with phosphate buffer $\left(0 \cdot 033 \mathrm{M}-\mathrm{Na}_{2} \mathrm{HPO}_{4} / \mathrm{KH}_{2} \mathrm{PO}_{4}\right)$. In no case were the concentrations at which lysis began appreciably affected by the $\mathrm{pH}$ value or by the presence of the phosphate buffer.

Effect of antibacterial substances. $\mathrm{HgCl}_{2}$ was found by Mager, Kuczynski, Schatzberg \& Avi-Dor (1956) to inhibit the 'optical effect' which accompanied the transfer of bacteria to solutions of higher osmotic pressure. To test its effect on the lysis reaction, Vibrio costicolus organisms were incubated in $10^{-5} \mathrm{M}-\mathrm{HgCl}_{2}$ for $15 \mathrm{~min}$. before subjection to osmotic shock in solutions of $\mathrm{NaCl}$ and KCl. This treatment did not alter the optical density curves.

Robinson, Gibbons \& Thatcher (1952) suggested that tetramethyl-pphenylenediamine (TMPPD) might inhibit a system maintaining a differential in salt concentration across the cell wall of Micrococcus halodenitrificans. To examine the effect of TMPPD on lysis of Vibrio costicolus, 0.003 M-TMPPD was added to the suspensions $\mathbf{1 5}$ min. before diluting in $\mathrm{NaCl}$ and $\mathrm{KCl}$ solutions. In a few minutes the suspension became very viscous, apparently as the result of lysis. To avoid this, TMPPD was added to the salt solutions into which organisms were pipetted to produce osmotic shock. It was necessary to add ascorbic acid to decolorize the suspensions before measuring the optical density. Under these conditions TMPPD had little effect on the resulting lysis curves. 
Cetyltrimethylammonium bromide (CTAB) is known to disorganize the cytoplasmic membrane of bacteria (Salton, 1951) and was tested for its effects on the osmotic lysis of Vibrio costicolus. CTAB was added to the stock suspension $2 \mathrm{~min}$. before the dilution experiments began; at a concentration of $650 \mu \mathrm{g} . / \mathrm{ml}$. the organisms lysed rapidly and the stock suspension cleared. However, the suspension remained stable on addition of $200 \mu \mathrm{g}$. CTAB $/ \mathrm{ml}$. but when subjected to osmotic shock the lysis curves were abnormal, as shown in Fig. 3. In $\mathrm{NaCl}$ and in $\mathrm{KCl}$ solutions the treated organisms were much more resistant to osmotic shock.

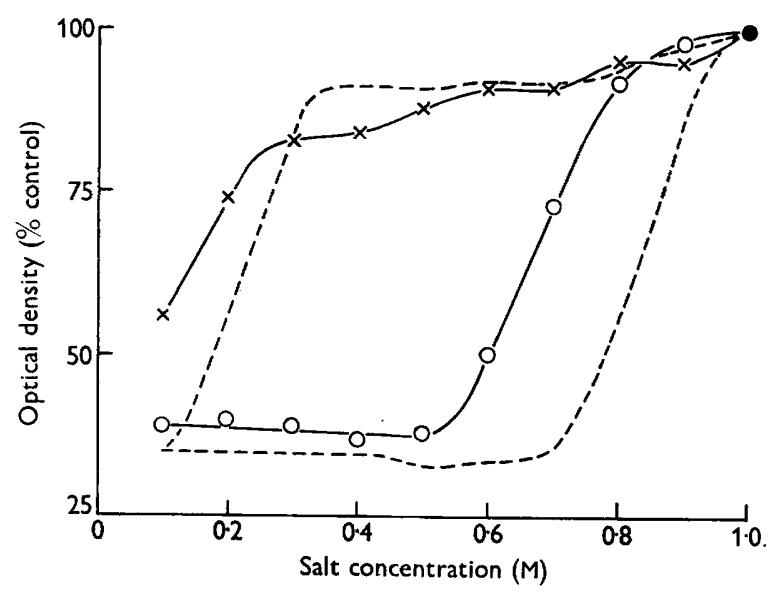

Fig. 3

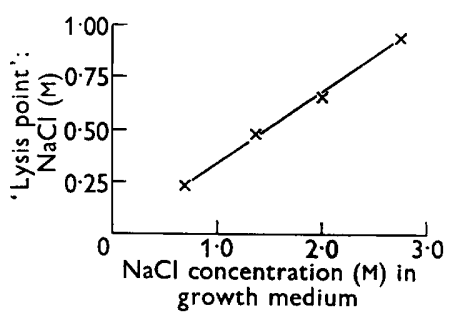

Fig. 4

Fig. 3. Effect of cetyltrimethylammonium bromide $(200 \mu \mathrm{g} . / \mathrm{ml}$.) on lysis of Vibrio costicolus. $\times, \mathrm{NaCl} ; \mathrm{O}, \mathrm{KCl}$. Continuous lines, with $\mathrm{CTAB}$; broken lines, controls without CTAB, from Fig. 2. Organisms were grown in medium containing $\mathrm{M}-\mathrm{NaCl}$.

Fig. 4. Relationship between $\mathrm{NaCl}$ concentration at which lysis of Vibrio costicolus began and that in which the organisms were grown.

Influence of the sodium chloride content of the growth medium. For all experiments discussed so far, organisms were grown in media containing $\mathrm{M}-\mathrm{NaCl}$. When the growth medium contained $2 \cdot 0 \mathrm{M}-\mathrm{NaCl}$ and the organisms were suspended in $2.0 \mathrm{M}$ salt solutions before dilution to concentrations 2.0 to $0.2 \mathrm{M}$, the form of the curves in $\mathrm{NaCl}$ and in $\mathrm{KCl}$ was the same as found in the M system but all concentrations had been doubled and lysis began at twice the concentration found previously.

The lysis points were determined for logarithmic phase organisms grown in a range of salt concentrations, and are shown in Fig. 4. Within the limits of accuracy of this technique, the concentration of $\mathrm{NaCl}$ at which lysis began was about one-third of the salt concentration of the medium in which the organisms had been grown.

Effect of transfer to higher concentrations of salts. In all the experiments described above, organisms were suspended in salt solutions equimolar with the salt concentration of the growth medium and lysis began when the $\mathrm{NaCl}$ concentration was decreased to one-third of this. To determine the stability 
of this relationship, organisms grown in M-salt medium were suspended in $2 \cdot 0 \mathrm{M}$ solutions of $\mathrm{NaCl}$ or $\mathrm{KCl}$ before being subjected to osmotic shock. The results are shown in Fig. 5. Although the upper portions of both curves fall quite steeply as a result of changes in cell volume with concentration, the curves retain the points of inflexion relevant to the salt concentration in which they had grown. This is best seen in the curve for organisms diluted in $\mathrm{KCl}$ solutions.

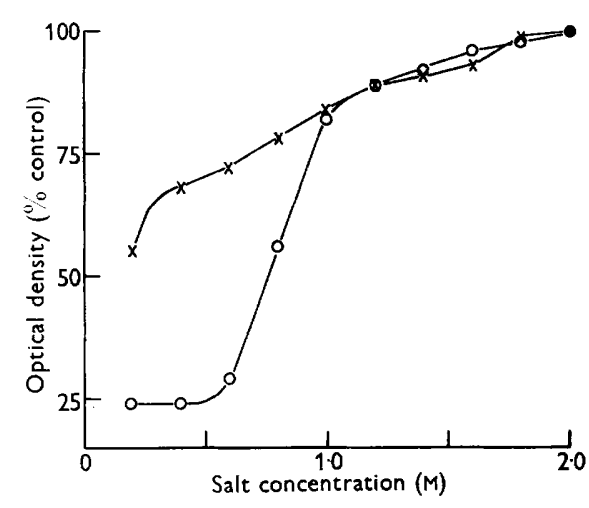

Fig. 5

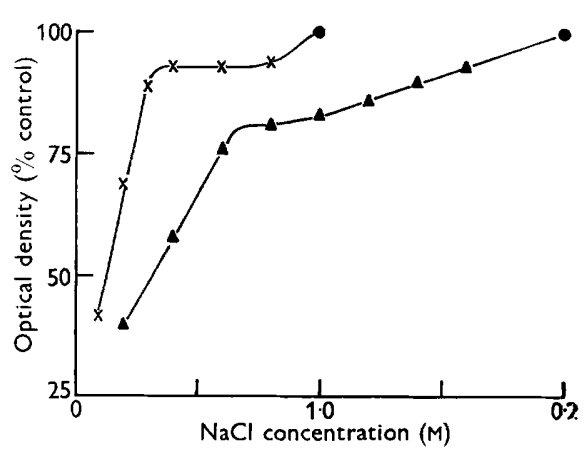

Fig. 6

Fig. 5. Effect of exposing Vibrio costicolus before osmotic shock to salt concentrations higher than that in which they were grown. Organisms were grown in media containing $\mathrm{M}-\mathrm{NaCl}$ and suspended in $2.0 \mathrm{M}$ solutions of $\mathrm{NaCl}(x)$ or $\mathrm{KCl}(O)$.

Fig. 6. Effect of exposing Vibrio costicolus before osmotic shock to NaCl concentration lower than that in which they were grown. $\times$, grown in $2.0 \mathrm{M}-\mathrm{NaCl}$ media and suspended in $\mathrm{M}-\mathrm{NaCl} ; \Delta$, grown in $2 \cdot 0 \mathrm{M}-\mathrm{NaCl}$ and suspended in $2 \cdot 0 \mathrm{M}-\mathrm{NaCl}$.

It is noteworthy that the organisms had apparently reached osmotic equilibrium on brief transfer to the more concentrated solution, for the upper descending portions of the curves in Fig. 5, continuous with the lower portion, may be taken to indicate reversal of that equilibrium. But the equilibration plainly did not adjust the organisms to the state they would have had if grown at the higher concentration, for the lysis point remained unchanged.

Effect of transfer to lower concentrations of salts. The effect of decreasing the salt concentration of the suspension before the lysis experiment was also investigated. Suspensions of organisms in $\mathrm{KCl}$ solutions could not be diluted appreciably without lysis but suspensions in $\mathrm{NaCl}$ solutions could be diluted safely to half the concentration of the growth medium. Vibrio costicolus grown in media containing $2.0 \mathrm{M}-\mathrm{NaCl}$ were suspended in $2.0 \mathrm{M}-\mathrm{NaCl}$. Part of this suspension was used to obtain a control lysis curve. The remainder was diluted with water to give a suspension in $\mathrm{m}-\mathrm{NaCl}$ and these organisms were immediately subjected to further osmotic shock. Figure 6 shows that this treatment gave a curve identical in shape and lysis point with that obtained with organisms grown in $\mathrm{M}$-salt solution. This type of experiment was repeated with organisms grown in various concentrations of $\mathrm{NaCl}$. In all cases the onset of lysis was related not to the salt concentration during growth but to the 
subsequent lower concentration in the stock suspension. The period during which organisms remained at the lower salt concentration was very short (less than $2 \mathrm{~min}$.) but, in this time, they apparently reached complete osmotic harmony with the new environment, i.e. a state apparently equivalent to that attained during growth at the lower concentration.

\section{B. Correlation of lysis with optical density changes}

In the data on the effects of osmotic shock on Vibrio costicolus presented so far, it has been assumed that optical density measurements provided an accurate assessment of lysis. Several experiments were performed to test the validity of this assumption.

Reversal of changes in optical density. There was a decrease in optical density of about $10 \%$ as the concentration of $\mathrm{NaCl}$ in which the organisms were suspended was reduced from 1.0 to $0 \cdot 4 \mathrm{M}$ (Fig. 1). If this change were due to osmotic swelling, restoration of the salt concentration to $\mathrm{M}$ should restore these optical density values to that of the control. Of organisms which had been subjected to concentrations below the lysis point, only that proportion which had not lysed would be expected to shrink on being transferred to molar solutions. Thus the observed changes in optical density should be reversible with whole organisms and irreversible with lysed preparations. After suspensions had been pipetted into $\mathrm{NaCl}$ or $\mathrm{KCl}$ solutions in the standard manner, concentrated solutions of the appropriate salt were added to restore the concentrations to molar, the final concentration of organisms was the same in all samples. The new relationship between optical density and the initial degree of osmotic shock is shown in Fig. 7. In $\mathrm{NaCl}$, some reversal of the optical effect occurred at all degrees of osmotic shock. In most suspensions the optical density increased to values above that of the control and there was considerable reversal even in suspensions at concentrations below the lysis point. Since the organisms equilibrate rapidly to lower salt concentrations, the degree of shrinkage when transferred back to a higher concentration would be greater than expected. The highest readings were for organisms which had been subjected to $\mathrm{NaCl}$ concentrations between 0.3 and $0.4 \mathrm{M}$, i.e. at concentrations near the lysis point. Below this point, fewer intact organisms remained, but these could undergo greater shrinkage. Thus the result is a balance between lysis and shrinkage, and the peak of optical density between 0.3 and $0.4 \mathrm{M}$ indicates that this is, in fact, the point at which lysis begins. On the other hand, the optical changes of suspensions diluted in $\mathrm{KCl}$ were not reversed under these conditions. It may be concluded that the type of equilibration to lower concentrations found in $\mathrm{NaCl}$ suspensions does not occur in $\mathrm{KCl}$ suspensions, due perhaps to more permanent damage to the plasma membrane during osmotic shock.

Viability of treated organisms. As a further check on the interpretation of optical density/salt concentration curves, the effect of osmotic shock on viability was investigated. Organisms grown in medium containing $\mathrm{M}-\mathrm{NaCl}$ were shocked in $\mathrm{NaCl}$ solutions and plated on proteose peptone tryptone agar containing $\mathrm{M}-\mathrm{NaCl}$. Figure 8 shows that there was a striking loss of viability 
in $\mathrm{NaCl}$ concentrations well above the lysis point. In contrast, there was close agreement between viability and optical density for cells diluted in $\mathrm{KCl}$. The data of Fig. 8 were obtained with very dilute suspensions. The counts were made by direct plating of the experimental suspensions, serial dilutions being unnecessary. When more concentrated suspensions were used, the decrease of viability with decrease in $\mathrm{NaCl}$ concentration was much more marked. It appeared, therefore, that organisms transferred to lower salt concentrations were extremely fragile, and that the manipulations involved in serial dilution had a drastic effect on their viability.

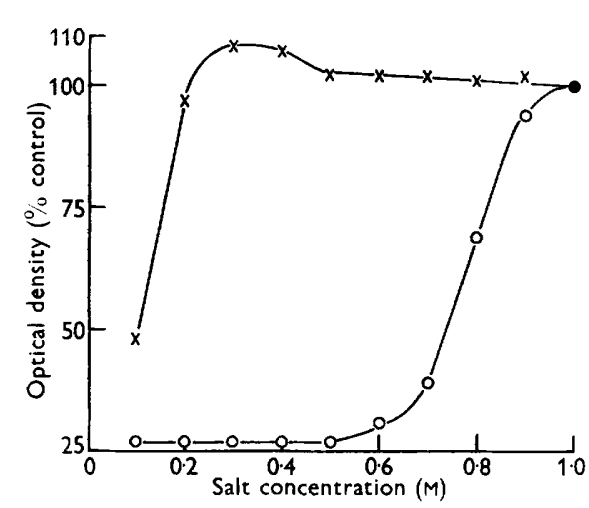

Fig. 7

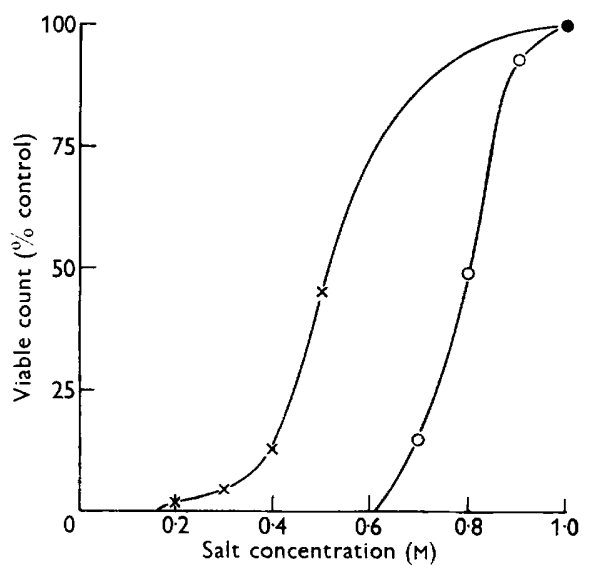

Fig. 8

Fig. 7. Reversibility of osmotic lysis of Vibrio costiculus. Organisms from $\mathrm{M}-\mathrm{NaCl}$ medium were subjected to osmotic shock in $\mathrm{NaCl}(x)$ and $\mathrm{KCl}(\mathrm{O})$ solutions. The concentrations of shocked suspensions were restored to molar by addition of the appropriate salt and the optical densities measured. The concentrations given in the figure refer to those used to produce the osmotic shock.

Fig. 8. Effect of osmotic shock on the viability of Vibrio costicolus suspended in solutions of $\mathrm{NaCl}(X)$ and $\mathrm{KCl}(O)$. Organisms were grown in medium containing $\mathrm{M}-\mathrm{NaCl}$.

The discrepancies between the optical density values and the viability count of shocked organisms cast some doubt on the validity of the former as measurements of degree of lysis. In an attempt to reconcile these differences, organisms subjected to varying degrees of osmotic shock in sodium chloride were examined by phase contrast microscopy.

Microscope examination of osmotically' shocked' organisms. Organisms from $\mathrm{NaCl}$ concentrations between $0 \cdot 6$ and $1 \cdot 0 \mathrm{M}$ appeared to be normal and intact. Those from concentrations below $0 \cdot 3 \mathrm{M}$ were mostly disrupted and appeared as ghosts; much debris was also seen in these preparations. Organisms from intermediate salt concentrations were of greatest interest. Some were large, and showed considerable distortion. Close examination revealed that in the majority of such organisms the structural wall had ruptured; the distortion was due to the extrusion of cytoplasm, which appeared to be retained within the plasma membrane, and which bulged through breaks in the cell wall. These breaks usually occurred terminally, but in some were nearly central. 
Since the organisms had been harvested in the logarithmic phase of growth, they were in all stages of development, and weak points might be expected to occur at various places in the wall. These structures appear to be identical with the plasmoptysis figures first described by Fischer (1900) and discussed by Knaysi (1951), by Mitchell \& Moyle (1956) and Weibull (1956). Fischer observed these bodies in growing cultures of Vibrio cholerae and $V$. proteus, but they could also be produced by transferring organisms to hypotonic solutions and by suspending organisms in solutions to whose solutes the plasma membrane was permeable. Fischer deduced that if the cell wall could not swell sufficiently it cracked and the cytoplasm was extruded. Plasmoptysis bodies were not viable.

Thus, in the present experiments, although the cell wall was fractured and the organism no longer viable, the cell membrane continued to hold the cytoplasm. Since lysis consists of the liberation of cytoplasmic contents into the suspending medium, such organisms have not lysed and continue to act as osmometers, as borne out by the reversal of optical density changes on restoration of the original external osmotic pressure. Hence optical density is a reliable guide to the degree of lysis produced by osmotic shock.

\section{DISCUSSION}

It will be clear that, though these lytic phenomena are in essence osmotic, they cannot be explained in simply osmotic terms. Lysis was influenced by the cation rather than the anion, and there were outstanding differences in the osmotic sensitivity of the organisms to different cations. Further, the mere removal of water by osmotic means does not, apparently, modify the lysis pattern.

The striking differences in response to $\mathrm{NaCl}$ and $\mathrm{LiCl}$ on the one hand and to $\mathrm{KCl}$ and $\mathrm{NH}_{4} \mathrm{Cl}$ on the other find a parallel in data of Pratt \& Riley (1955) obtained with a marine bacterium. The superior protection provided by the sodium ion is not attributable to the saline habitat of their strain and ours, since the same difference between cations has been observed with the non-halophilic Vibrio metchnikovi (unpublished data). A more likely explanation lies in the greater ease with which the cations of smaller hydrated ionic radii (potassium and ammonium) penetrate the plasma membrane (Boyle \& Conway, 1940). The swelling of cells which follows transfer to hypotonic solutions may deform the membrane sufficiently for the smaller particles to enter the cells. The ensuing uptake of water may then result in plasmoptysis. Conversely, the decrease in osmotic sensitivity which followed pretreatment with CTAB was probably the result of leakage of osmotically-active solutes from the cell.

The sharp decrease in degree of viability on dilution is a warning against the use of hypotonic diluents and unsuitable solutes where accurate counts of viable organisms are required. That this dramatic effect is not confined to halophilic bacteria has been demonstrated recently by Marshall \& Scott (1958) with Vibrio metchnikovi.

Since simple transfer to solutions of higher $\mathrm{NaCl}$ concentration did not increase the lysis point of Vibrio costicolus there can be no influx of substances 
tending to bring the internal state of the organisms into adjustment with the new environment, such as must occur during growth. Presumably water is lost on simple transfer but is restored on dilution during the lysis experiment, and hence does not affect the final result. Similar attempts to increase the lysis point of non-proliferating organisms exposed to higher $\mathrm{NaCl}$ concentrations by aerobic incubation with oxidizable substrates were unsuccessful even in the presence of potassium phosphates.

The apparently complete adjustment which promptly follows transfer to moderately lower salt concentrations, as shown by the changed lysis point, is probably due to leakage of osmotically active solutes while the organisms are swollen. Such solutes would be small ions or molecules. Bacteria are rich in potassium, and lysis experiments in $\mathrm{KCl}$ solutions suggest that this ion penetrates the plasma membrane rapidly when the cell is subjected to an osmotic stress. Hence the change in cellular potassium content was measured when the $\mathrm{NaCl}$ concentration of the suspension was halved. About one-third of the potassium was lost, suggesting that this ion may be of major importance in osmotic regulation of bacterial cells. Evidence supporting this suggestion has also been obtained from potassium accumulation studies with Salmonella oranienburg (Christian, 1955).

The constant relationship between the $\mathrm{NaCl}$ concentrations of the growth medium and of the suspending solution at the onset of lysis shows that the osmotic status of the organism is directly related to that of the environment. Lysis of Vibrio metchnikovi, a non-halophile, also begins at $\mathrm{NaCl}$ concentrations close to one-third of the concentration during growth (unpublished observations). Hence the internal osmotic status of these two species are similar. This supports the conclusion based on cryoscopic data (Christian \& Ingram, 1959) that the explanation of halophilism does not lie in an ability to maintain a relatively small internal concentration of salts.

This work was carried out as part of the programme of the Food Investigation Organization of the Department of Scientific and Industrial Research during the tenure by one of us (J.H.B.C.) of an Overseas Studentship of the Commonwealth Scientific and Industrial Research Organization, Australia.

\section{REFERENCES}

Boyle, P. J. \& Conway, E. J. (1940). Potassium accumulation in muscle and associated changes. J. Physiol. 100, 1.

Christian, J. H. B. (1955). The water relations of growth and respiration of Salmonella oranienburg at $30^{\circ}$ C. Aust. J. Biol. Sci. 8, 490.

Christian, J. H. B. \& Ingram, M. (1959). The freezing points of bacterial cells in relation to halophilism. J. gen. Microbiol. $20,27$.

Fischer, A. (1900). Die Empfindlichkeit der Bakterienzelle und das baktericide Serum. Z. Hyg. InfektKr. 35, 1.

KNAYSI, G. (1951). Elements of Bacterial Cytology, 2nd ed. Ithaca, New York: Comstock.

Mager, J., Kuczynski, M., Schatzberg, G. \& Avi-Dor, Y. (1956). Turbidity changes in bacterial suspensions in relation to osmotic pressure. J. gen. Microbiol. 14, 69. 
Marshall, B. J. \& Scott, W. J. (1958). The water relations of Vibrio metchnikovi at $30^{\circ}$ C. Aust. J. biol. Sci. $11,171$.

Mitchell, P. \& Moyle, J. (1956). Osmotic structure and function in bacteria. In Bacterial Anatomy. Symp. Soc. gen. Microbiol. 6, 150.

Pratt, D. \& Riley, W. (1955). Lysis of a marine bacterium in salt solutions. Bact. Proc. 55, 26.

Robinson, J., Gibbons, N. E. \& Thatcher, F. S. (1952). A mechanism of halophilism. in Micrococcus halodenitrificans. J. Bact. 64, 69.

Robinson, J. \& Katzinelson, H. (1953). Aspartate-glutamate transaminase in a red halophilic bacterium. Nature, Lond. 172, 672 .

Salton, M. R. J. (1951). The adsorption of cetyltrimethylammonium bromide by bacteria, its action in releasing cellular constituents and its bactericidal effects. J. gen. Microbiol. 5, 391.

Smithies, W. R., Gibbons, N. E. \& Bayley, S. T. (1955). The chemical composition of the cell and cell wall of some halophilic bacteria. Canad. J. Microbiol. 1, 605.

WeIrull, C. (1956). Bacterial protoplasts: their formation and characteristics. In Bacterial Anatomy. Symp. Soc. gen. Microbiol. 6, 111.

(Received 24 June 1958) 